\title{
Chemical profiles of the active fraction from Prinsepia utilis Royle leaves and its anti- benign prostatic hyperplasia evaluation in animal models
}

\author{
Ying Peng ${ }^{\dagger}$, Chongsheng Peng ${ }^{\dagger}$, Yang Wu, Chongzhi Sun and Xiaobo Li ${ }^{*}$
}

\begin{abstract}
Background: The Prinsepia utilis Royle leaves (P. utilis) is a folk herb used for benign prostatic hyperplasia (BPH) control by ethnic minorities for centuries in China with rich in resources. Our previous studies have confirmed the anti-BPH effect of its water extract (QCJ) and the active fraction (Fr. B) separated from the QCJ by animal test. The Fr. B from P. utilis should be a potential candidate for BPH control.

Methods: In this study, the chemical ingredients of Fr. B were identified by UPLC-QTOF-MS, and quantified by HPLC. Murine animal models were divided into 8 groups, Sham rats, BPH rats, BPH rats administered with finasteride $(1 \mathrm{mg} /$ $\mathrm{kg}), \mathrm{BPH}$ rats administered with Pule'an $(460 \mathrm{mg} / \mathrm{kg}), \mathrm{BPH}$ rats administered with low, high dosage of QCJ $(860 \mathrm{mg} / \mathrm{kg}$, $2580 \mathrm{mg} / \mathrm{kg}$ respectively), BPH rats administered with low, high dosage of Fr. B (160 mg/kg, $480 \mathrm{mg} / \mathrm{kg}$ respectively). The expression of vascular endothelial growth factor (VEGF) in the prostate tissue of rats was tested, and serum levels of dihydrotestosterone (DHT), testosterone (T), estradiol (E2), interleukin-6 (IL-6), tumor necrosis factor- $a(\mathrm{TNF}-\mathrm{a})$ and total superoxide dismutase (SOD), glutathione peroxidase (GSH-Px), catalase (CAT), malondialdehyde (MDA) in prostate homogenate were measured. One-way ANOVA followed by LSD was used for statistical analysis.

Results: The BPH rats treated by Fr. B exhibited significant reductions of VEGF and MDA levels, as well as significant increases of SOD, GSH-Px and CAT in the prostate tissue after 28 day administration $(P<0.05)$. Moreover, Fr. B significantly reduced DHT, DHT/E2 ratio, TNF-a, while increased T levels in serum of BPH rats $(P<0.05)$. UPLC-QTOF-MS analysis revealed 10 flavonoids as the key constituents of this fraction, which accounted for $54.96 \%$ of all substance of Fr. B. The relative contents of compound 1, 2 are 11.1\%, 13\% in Fr. B respectively.

Conclusions: These results indicated that the Fr. B obtained from P. utilis alleviated the symptoms of BPH rats through multiple mechanisms including reduction of DHT/E2 ratio, inhibition of growth factor, anti-inflammation and anti-oxidation, in which flavonoids might be the key constituents. It supported the hypothesis that the Fr. B should be further explored as a candidate for BPH patients.
\end{abstract}

Keywords: Prinsepia utilis Royle, Flavonoid, Benign prostatic hyperplasia, UPLC-QTOF-MS, Quantification

\section{*Correspondence: xbli@sjtu.edu.cn}

†Ying Peng and Chongsheng Peng contributed equally to this work. School of Pharmacy, Shanghai Jiao Tong University, No. 800 Dongchuan Road, Minhang District, Shanghai 200240, People's Republic of China

\section{Background}

Prinsepia utilis Royle (P. utilis) is belonged to prinsepia genus (rosaceae), mainly distributed in southwest China such as Yunnan and Guizhou province. It is a food medicine homologous plant, of which the roots, leaves and 
fruits are traditionally used to treat toothache, carbuncle and gangrene [1]. Pharmacological studies showed that the stems and leaves of $P$. utilis had the functions of anti-osteoporosis [2], regulating blood lipids [3], antitumor [4], anti-oxidation [2], anti-inflammation [5], antibacteria [6], etc. Interestingly, as a multi-ethnic herb, the leaves of $P$. utilis is used as tea in folk for benign prostatic hyperplasia (BPH) symptom control by Naxi, Bai, $\mathrm{Yi}$, Mosuo and other ethnic minorities for centuries in Yunan province.

Generally, BPH is considered to be a product of androgen action upon an aging prostate. But longitudinal epidemiological studies showed that androgen levels were unlikely to be solely responsible [7]. There are many potential etiological factors contributing to BPH pathogenesis such as inflammation, oxidative stress, imbalance between prostate cell growth and apoptosis $[8,9]$. Our previous studies confirmed the anti-BPH activities of $P$. utilis leaves extract (QCJ) on $\mathrm{BPH}$ rats and the Fr. B separated from QCJ as the active fraction [10]. However, whether its anti-BPH activity is related to anti-inflammation, anti-oxidation or anti-androgenic need further study.

According to the chemical reports on P. utilis, flavonoids, amino acids, steroids and terpenoids have been isolated from $P$. utilis fruit, stems and leaves [11]. The content of total flavonoids is up to be $7.25 \%$ in $P$. utilis fruit [12], 3\% in stems and leaves of P. utilis [13]. The flavonoids usually exhibited potent anti-inflammatory and antioxidant properties. It was reported that flavonoid-rich fraction from $P$. utilis fruits exhibited strong radical scavenging activities [14]. Many medicinal plants rich in flavonoids showed well anti-BPH potential [15, 16], which were reported to exert BPH protective effect through regulating inflammatory responses and reducing oxidative stress.

Therefore, these findings led us to further analyze the chemical ingredients of Fr. B with UPLC-QTOF-MS, assess its therapeutic effects on testosterone-induced $\mathrm{BPH}$ rats by oral administration of Fr. B and compared with finasteride and Pule'an used as first-line therapy in China in terms of its efficacy and possible mechanisms as anti-androgenic, anti-oxidant and anti-inflammatory in this study.

\section{Materials and methods}

\section{Extraction and isolation of Fr. B}

P. utilis leaves was collected from Dali, Yunnan, China and authenticated by one of the authors Xiaobo Li. Voucher specimen has been deposited at herbarium of School of Pharmacy, Shanghai Jiao Tong University, Shanghai, China. Preparation of Fr. B was previously described by Wu et al [10]. Dried and powdered leaves
$(2 \mathrm{~kg})$ were re-fluxed 3 times with distilled water. The combined extraction was filtrated and then concentrated under reduced pressure to obtain a crude aqueous extract (QCJ). The sample was redissolved, and then separated by macroporous resin $\mathrm{AB}-8$. After adsorption, the resin was washed with $5 \%$ ethanol without collection, followed by $40 \%$ ethanol, the elution was then evaporated under vacuum at $65^{\circ} \mathrm{C}$ and lyophilized to obtain Fr. B.

\section{UPLC-QTOF-MS analysis of Fr. B}

The qualitative chemical profiles of Fr. B was analyzed by UPLC-QTOF-MS in MS ${ }^{\mathrm{E}}$ mode which was performed on a Waters ACQUITY UPLC I-Class system (Waters Corp., Milford, MA, United States) with an ACQUITY UPLC BEH C18 column $(100 \times 2.1 \mathrm{~mm}, 1.7 \mu \mathrm{m}$, Waters Corp., United States) by gradient elution using $0.1 \%$ formic acid in water (A) and $0.1 \%$ formic acid in acetonitrile (B) at a flow rate of $0.4 \mathrm{ml} / \mathrm{min}$. The gradient profile was $0-2 \mathrm{~min}$ (A: $90 \%), 2-9 \min$ (A: $90-80 \%), 9-11 \min$ (A: $80-65 \%$ ), 11-14 min (A: 65-0\%). The injection volume was $1 \mu \mathrm{l}$. The temperature of the column oven was set to $45^{\circ} \mathrm{C}$. Mass spectrometry was carried out using a Waters VION IMS QTOF mass spectrometer (Waters Corp., Milford, MA, United States). Ionization was performed in both positive and negative electrospray ionization (ESI) mode. The MS parameters were as follows, capillary voltage, $2.5 \mathrm{kV}$; cone voltage, $40 \mathrm{~V}$; source temperature, $115^{\circ} \mathrm{C}$; desolvation temperature, $450^{\circ} \mathrm{C}$; gas flows of cone and desolvation, 50 and 900 l/h. A MSE (Mass Spectrometry Elevated Energy) experiment in two scan functions was carried out as follows. Function 1 (low energy), m/z 50-1000, $0.2 \mathrm{~s}$ scan time, $0.02 \mathrm{~s}$ inter-scan delay, $4 \mathrm{eV}$ collision energy. Function 2 (high energy), $\mathrm{m} / \mathrm{z} 50-1000,0.2 \mathrm{~s}$ scan time, $0.02 \mathrm{~s}$ inter-scan delay, collision energy ramp of $20-45 \mathrm{eV}$. The data were processed using UNIFI 1.8.1 software (Waters Corp., Milford, MA, United States).

\section{Quantitative analysis of Fr. B}

The quantitative analysis of Fr. B were performed on an Agilent 1200 HPLC (high-performance liquid chromatography) system, equipped with a quaternary solvent delivery system, an on-line degasser, an autosampler, a column temperature controller, and a DAD (photodiode-array-detector) detector. Agilent Zorbax SB-C18 column $(5 \mu \mathrm{m}, 4.6 \times 250 \mathrm{~mm})$ was employed during the experiment with a flow rate of $1.0 \mathrm{ml} / \mathrm{min}$. The column temperature was maintained at $30^{\circ} \mathrm{C}$, and the injection volume was $10 \mu \mathrm{l}$. The mobile phase was composed of water (A) and acetonitrile (B) with the following gradient elution: $0-10 \mathrm{~min}, 95 \% \mathrm{~A} ; 10-15 \mathrm{~min}, 95-90 \% \mathrm{~A}$; 15-20 min, $90 \%$ A; $20-30 \mathrm{~min}, 90-85 \%$ A; $30-40 \mathrm{~min}$, 85-80\% A; 40-50 min, 80-75\% A; 50-60 min, 75-70\% A; $60-70 \mathrm{~min}, 70-0 \% \mathrm{~A}$. The wavelength was set at $360 \mathrm{~nm}$. 


\section{Animals and BPH models}

Male Spraue-Dawley rats (180-220g) were procured from Shanghai Slac Laboratory Animal Co. Ltd. (Shanghai, China), and housed in the Laboratory Animal Center of Shanghai Jiao Tong University (Shanghai, China). The animals were housed in groups under controlled room temperature $\left(25 \pm 2{ }^{\circ} \mathrm{C}, 55 \pm 10 \%\right.$ relative humidity) with a 12/12 h light/dark cycle. Standard laboratory chow and water were available ad libitum. All experimental procedures were approved by the Animal Ethics Committee of Shanghai Jiao Tong University (Shanghai, China). All methods are reported in accordance with ARRIVE guidelines (https://arriveguidelines.org) for the reporting of animal experiments.

Following 1 week acclimation, rats were randomly assigned to 8 groups $(n=10)$ as following, Sham, BPH model, Finasteride, Pule'an, Low QCJ, High QCJ, Low Fr. B, High Fr. B. The scrotum of the sham animals were cut following sewing up without cutting off the both testicles. Rats in the other groups were castrated. After incision disinfection with penicillin for 1 week, sham rats were treated with saline (s.c., $0.5 \mathrm{ml} / \mathrm{kg}$, alternate days) and $0.5 \%$ CMC-Na (i.g. $10 \mathrm{ml} / \mathrm{kg}$, daily). $\mathrm{BPH}$ group rats were received testosterone propionate (s.c., $10 \mathrm{mg} / \mathrm{kg}$ ) alternate days and 0.5\% CMC-Na (i.g. $10 \mathrm{ml} / \mathrm{kg}$ ) daily for 4 weeks $[17,18]$. Two positive groups, the rats were treated with testosterone propionate (s.c., $10 \mathrm{mg} / \mathrm{kg}$ ) and received a treatment with finasteride (i.g., $1 \mathrm{mg} / \mathrm{kg}$ ) or Pule'an (i.g., $460 \mathrm{mg} / \mathrm{kg}$ ). Low/High QCJ group rats were treated with testosterone propionate (s.c., $10 \mathrm{mg}$ / $\mathrm{kg}$ ) and received a treatment with QCJ (i.g., $860 \mathrm{mg} / \mathrm{kg}$ or $2580 \mathrm{mg} / \mathrm{kg}$ respectively). Low/High Fr. B group rats were treated with testosterone propionate (s.c., $10 \mathrm{mg} / \mathrm{kg}$ ) and received a treatment with Fr. B (i.g., $160 \mathrm{mg} / \mathrm{kg}$ or $480 \mathrm{mg} /$ $\mathrm{kg}$ respectively). Low dosage of QCJ or Fr. B was clinically equivalent doses $(1.8 \mathrm{~g}$ Crude drug $/ \mathrm{kg})$. High dosage of QCJ or Fr. B was three times the clinical equivalent doses (5.4 g Crude drug/kg).

At the end of experiment, animals were sacrificed under anaesthesia after blood sample collection. The prostates were removed and ventral prostate tissues were fixed in $10 \%$ neutral buffered formalin and embedded in paraffin for both histological and immunohistochemical examinations. The remainder of each prostate was stored at $-80^{\circ} \mathrm{C}$ and used for further analyses.

\section{Histology and immunohistochemical localizatiion of vascular endothelial growth factor (VEGF)}

Prostate tissue were fixed for 1 day in paraformaldehyde solution ( $4 \%$ in phosphate-buffered saline (PBS) $0.1 \mathrm{M}$ ) at room temperature, dehydrated by graded ethanol and embedded in paraffin. Ten micrometres thick sections collected on glass slides, deparaffinized then stained with hematoxylin and eosin (H\&E) for histopathological examination using light microscopy (Olympus BX51, Japan) associated to an Imaging system (Image Pro Plus 6.0).

Slices were deparaffinized and immersed in freshly prepared $3 \% \mathrm{H}_{2} \mathrm{O}_{2}$, blocked with goat serum for $30 \mathrm{~min}$, then treated with citrate buffer. The sections were rinsed with PBS and incubated at $4{ }^{\circ} \mathrm{C}$ overnight with VEGF antibody (Boster Biological Technology, Wuhan, China.), incubated with secondary antibody (goat anti-Rabbit IgG, Boster Biological Technology, Wuhan, China.) at $37^{\circ} \mathrm{C}$ for $30 \mathrm{~min}$. After washed with PBS, the sections were incubated in strept avidin-biotin complex at $37^{\circ} \mathrm{C}$ for $30 \mathrm{~min}$, and immersed in diaminobenzidine for $5 \mathrm{~min}$. The haematoxylin-stained sections were dehydrated with ethanol and visualized with an optical microscope (Olympus BX51, Japan). The VEGF content was expressed as average optical density (IOD/Area).

\section{Evaluation of dihydrotestosterone (DHT), testosterone $(T)$, estradiol (E2), tumor necrosis factor- $a$ (TNF- $\alpha$ ), interleukin-6 (IL-6) in plasma}

DHT, $\mathrm{T}$ and $\mathrm{E}_{2}$ levels of the rats plasma were assayed with the commercially available kits (Shanghai Enzymelinked Biotechnology Co., Ltd., Shanghai, China). TNF- $\alpha$, IL-6 levels were assayed in plasma sample with the commercially available kits (MultiSciences Biotech Co., Ltd., Hangzhou, China). All the procedures were performed according to manufacturer' $s$ instructions of the kits.

\section{Evaluation of malondialdehyde (MDA), superoxide dismutase (SOD), glutathione peroxidase (GSH-Px), catalase (CAT) in prostate tissue}

Prostate samples were homogenized and assayed for MDA, SOD, GSH-Px and CAT using commercially available kits (MultiSciences Biotech Co., Ltd., Hangzhou, China). All the procedures were performed according to manufacturer's instructions of the kits.

\section{Statistical analysis}

All data were expressed as mean \pm standard deviation. The results were analyzed by one-way ANOVA followed by LSD for multiple comparisons using SPSS 21.0 software for Windows (SPSS Inc., Chicago, IL). A $P$ value of $<0.05$ was considered significant.

\section{Results}

\section{Chemical ingredients of Fr. B}

The BPI chromatograms of Fr. B by UPLC-QTOF-MS with both positive and negative ions were shown in Fig. 1. Ten flavonoid glycosides were assigned from Fr. 


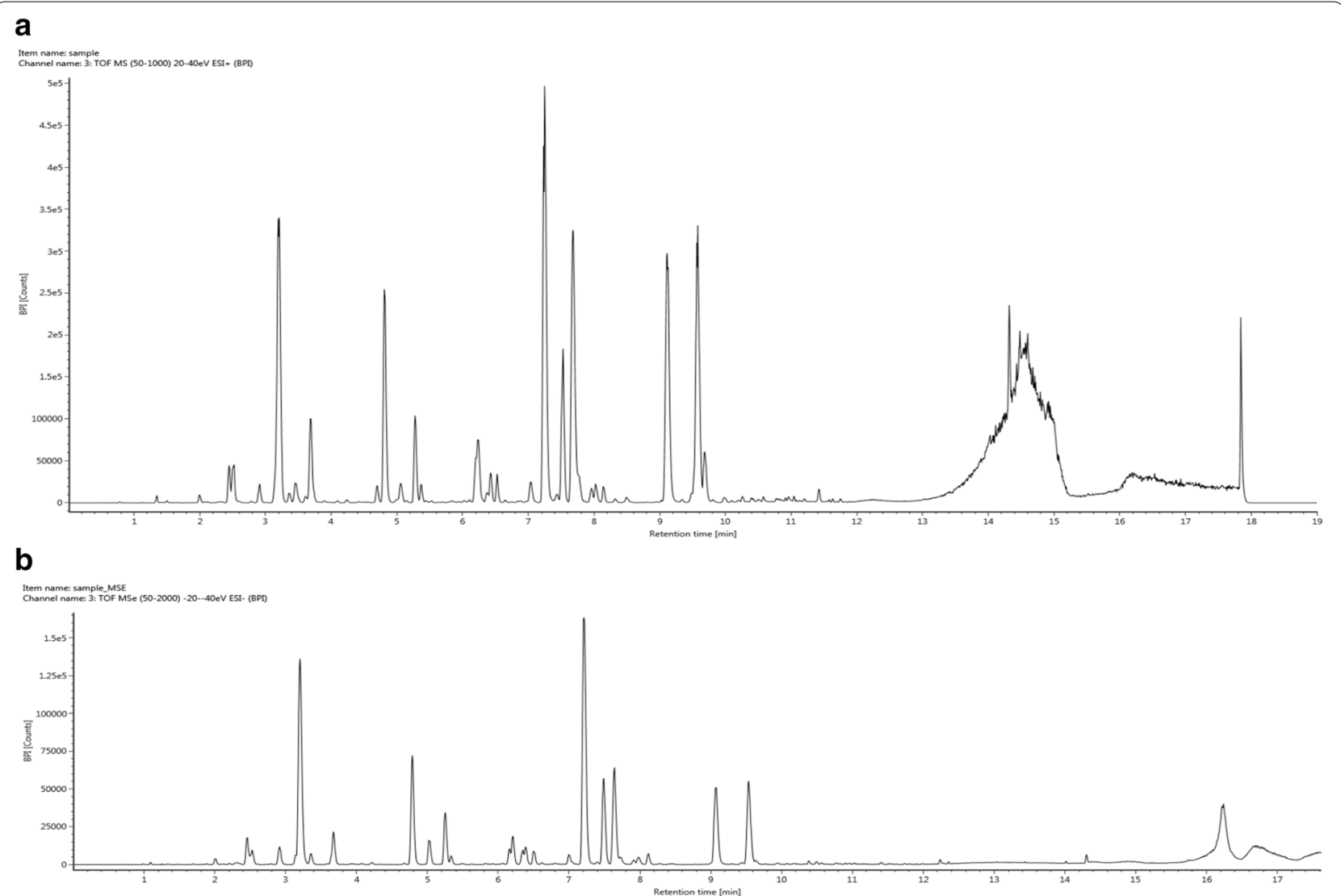

Fig. 1 The BPI chromatograms of Fr. B by UPLC-QTOF-MS. BPI chromatogram in positive ESI mode; b BPI chromatogram in negative ESI mode

B by their tandem mass data analysis of each peak in detail. Detailed information including retention time, accurate MS, and MS/MS fragmentions are listed in Table 1. Further, quantification of the 10 flavanoids glycosides in Fr. B was performed by HPLC with quercetin as internal standard, and compound 2 as index. The results showed that 10 flavonoid glycosides were accounted for $54.96 \%$ of all substance of Fr. B, in which compound 1 was with a relative content of $11.1 \%$, and compound 2 was with a relative content of $13 \%$ in Fr. B.

\section{Effect of Fr. B on prostate morphology of BPH rats}

There was no significant difference in rat weight among the groups along with the experiment. Prostate tissue collected from the sham rats showed normal architecture and histology, regular acini with cuboidal and low cylindrical epithelium with round nuclei showing basal alignment. While a significant disorganization of prostate tissue, irregular acinar shape with papillary projection into the lumen and foci of piling-up hyperplastic nodules were observed in the prostate tissue of rats after $\mathrm{BPH}$ induction. Finasteride, Pule'an, QCJ and Fr. B treatment could significantly improved the histological pattern and marked hyperplasia of prostate tissuein $\mathrm{BPH}$ rats (Fig. 2a). The expression of VEGF in the rat prostates was analyzed by immunohistochemical analysis. As shown in Fig. 2b, compared with the sham operation group, VEGF level in the prostate tissue of BPH group rats was significantly increased $(P<0.01)$. Finasteride, Pule'an, QCJ and Fr. B significantly reduced the expression of VEGF in the prostate of BPH rats $(P<0.01)$, and the high dose of QCJ and Fr. B decreased the VEGF level by 50.04 and $51.02 \%$, while low dose decreased the level of VEGF by 39.67 and $34.36 \%$ respectively, which indicated that QCJ and Fr. B might regulate the expression of VEGF to reduce the abnormal proliferation of prostate cells and alleviate $\mathrm{BPH}$.

\section{Effects of Fr. B on sex hormone levels in BPH rats serum}

The basal levels of DHT, $\mathrm{T}$ and $\mathrm{E}_{2}$ in serum of sham animals were showed in Fig. 3, those in serum collected from BPH animals showed marked increases $(P<0.01)$. Treatment with finasteride, Pule'an, QCJ and Fr. B considerably reduced DHT and DHT/ $\mathrm{E}_{2}$ levels $(P<0.01)$. However, significant increases were observed in T levels 
Table 1 Flavonoid glycosides profile of Fr. B as characterized by UPLC-QTOF-MS analysis in MSE mode

\begin{tabular}{|c|c|c|c|c|c|c|c|c|c|}
\hline peak & $t_{R}(\min )$ & formula & MW & {$[\mathrm{M}+\mathrm{H}]^{+}$} & MS/MS & {$[\mathrm{M}-\mathrm{H}]^{-}$} & MS/MS & Putative identity & reference \\
\hline 1 & 2.46 & $\mathrm{C}_{39} \mathrm{H}_{50} \mathrm{O}_{25}$ & 918.2641 & 919.2706 & $773,611,465,303$ & 917.2817 & $755,609,463,462,301,300$ & 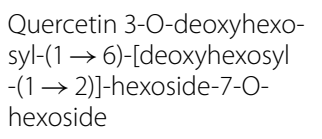 & [19] \\
\hline 2 & 3.20 & $\mathrm{C}_{39} \mathrm{H}_{50} \mathrm{O}_{24}$ & 902.2692 & 903.2755 & $757,595,449,287$ & 901.2599 & $739,593,447,446,285,284$ & $\begin{array}{l}\text { Kaempferol 3-O-deoxyhex- } \\
\text { osyl- }(1 \rightarrow 6)-[\text { deoxyhexosyl } \\
-(1 \rightarrow 2)]- \text { hexoside-7-O- } \\
\text { hexoside (compound } 1)\end{array}$ & [19] \\
\hline 3 & 3.67 & $\mathrm{C}_{33} \mathrm{H}_{40} \mathrm{O}_{21}$ & 772.2062 & 773.2111 & $627,465,303$ & 771.1976 & $609,463,301$ & $\begin{array}{l}\text { Quercetin 3-O-deoxyhex- } \\
\text { osyl-(1 } \rightarrow 6) \text {-hexoside } \\
\text {-7-O-hexoside }\end{array}$ & [19] \\
\hline 4 & 4.78 & $\mathrm{C}_{33} \mathrm{H}_{40} \mathrm{O}_{20}$ & 756.2113 & 757.2175 & $611,449,287,228$ & 755.2016 & $593,447,285$ & $\begin{array}{l}\text { Kaempferol 3-O-deox- } \\
\text { yhexosyl -(1 } \rightarrow \text { 6)-hexoside } \\
\text { - 7-hexoside }\end{array}$ & [20] \\
\hline 5 & 5.25 & $\mathrm{C}_{34} \mathrm{H}_{42} \mathrm{O}_{21}$ & 786.2219 & 787.2267 & $641,479,317$ & 785.2145 & $623,477,315$ & $\begin{array}{l}\text { Isorhamnetin 3-O- deox- } \\
\text { yhexosyl-(1 } \rightarrow \text { 6)-hexoside } \\
-7 \text {-O-hexoside }\end{array}$ & [19] \\
\hline 6 & 7.21 & $\mathrm{C}_{33} \mathrm{H}_{40} \mathrm{O}_{19}$ & 740.2164 & 741.2215 & $595,449,287$ & 739.2073 & $593,285,284$ & $\begin{array}{l}\text { Kaempferol 3-O-deox- } \\
\text { yhexosyl - }(1 \rightarrow 6) \text {-[deox- } \\
\text { yhexosyl- }(1 \rightarrow 2) \text {-hexoside } \\
\text { (compound } 2 \text { ) }\end{array}$ & [19] \\
\hline 7 & 7.48 & $\mathrm{C}_{34} \mathrm{H}_{42} \mathrm{O}_{20}$ & 770.2269 & 771.2328 & $625,479,317$ & 769.2176 & $623,315,314$ & $\begin{array}{l}\text { 3-O-deoxyhexosyl } \\
-(1 \rightarrow 6) \text {-[deoxyhexosyl } \\
-(1 \rightarrow 2)] \text { - hexoside }\end{array}$ & [19] \\
\hline 8 & 7.64 & $\mathrm{C}_{27} \mathrm{H}_{30} \mathrm{O}_{16}$ & 610.1534 & 611.1610 & 465,303 & 609.1450 & $463,301,300$ & $\begin{array}{l}\text { Quercetin 3-O-deoxyhexo- } \\
\text { syl -(1 } \rightarrow 6) \text {-hexoside }\end{array}$ & [19] \\
\hline 9 & 9.08 & $\mathrm{C}_{27} \mathrm{H}_{30} \mathrm{O}_{15}$ & 594.1585 & 595.1665 & 449,287 & 593.1495 & 447,285 & $\begin{array}{l}\text { Kaempferol 3-O-deoxyhex- } \\
\text { osyl - }(1 \rightarrow 6) \text {-hexoside }\end{array}$ & [19] \\
\hline 10 & 9.53 & $\mathrm{C}_{28} \mathrm{H}_{32} \mathrm{O}_{16}$ & 624.169 & 625.1756 & 479,317 & 623.1609 & 477,315 & $\begin{array}{l}\text { Isorhamnetin 3-O-deox- } \\
\text { yhexosyl -(1 } \rightarrow \text { 6)-hexoside }\end{array}$ & [19] \\
\hline
\end{tabular}

Compounds 1 and 2 were further determined by reference compounds

with QCJ and Fr. B administration $(P<0.05$, Fig. 4). DHT is converted by the steroid enzyme $5 \alpha$-reductase from $\mathrm{T}$ [21]. The production and accumulation of DHT in the prostate promote cell growth and induce hyperplasia [22]. The level of DHT in serum of rats was significantly lower than that of $\mathrm{BPH}$ rats, while the level of $\mathrm{T}$ was significantly higher, suggesting that Fr. B may play an anti-prostate hyperplasia role by inhibiting the production of DHT.

\section{Effects of Fr. B on inflammatory factors in BPH rats serum} As shown in Fig. 4, serum levels of TNF- $\alpha$ and IL-6 were markedly elevated in $\mathrm{BPH}$ rats $(P<0.05)$. Oral administration of finasteride, Pule'an, QCJ and Fr. B to $\mathrm{BPH}$ rats considerably reduced TNF- $\alpha$ levels $(P<0.01)$. Pule'an could significantly decrease IL-6 levels of BPH rats $(P<0.05)$. However, finasteride, QCJ and Fr. B groups showed decreasing trends in IL-6 levels without significant effect statistically (Fig. 4).
Effects of Fr. B on MDA, SOD, GSH-Px and CAT levels in BPH rats prostates tissues

As shown in Fig. 5, homogenates of the prostates tissues from sham animals had a basal levels of MDA, while that from BPH rats showed a marked increase $(P<0.01)$. Oral administration of finasteride, Pule'an, QCJ and Fr. B to $\mathrm{BPH}$ rats significantly decreased levels of MDA $(P<0.01)$. Moreover, we also observed that the contents of SOD, GSH-Px and CAT in BPH rats prostates were significantly reduced, these are three important endogenous antioxidants in the body. Administration of finasteride, Pule'an, $\mathrm{QCJ}$ and Fr. B to BPH rats could significantly increase SOD levels of BPH rats $(P<0.05)$. Similarly, treatment with finasteride, high dose of $\mathrm{QCJ}$ and Fr. B also demonstrated significant trends of protection increasing the reduced levels of CAT and GSH-Px $(P<0.05)$ as well, whereas Pule'an group showed an increasing trend without statistically significance. 


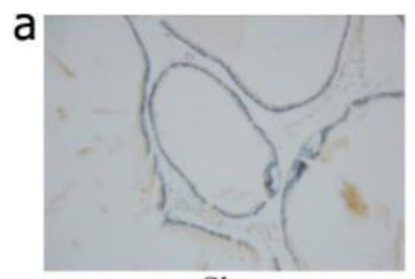

Sham

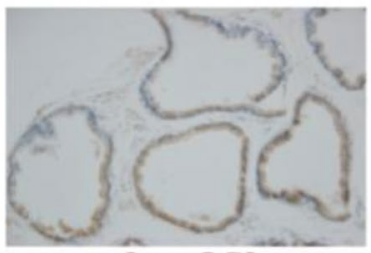

Low-QCJ

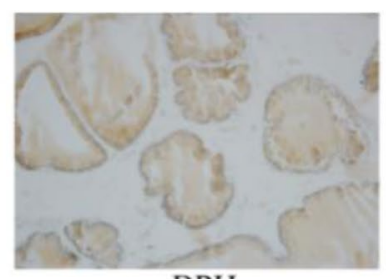

$\mathrm{BPH}$

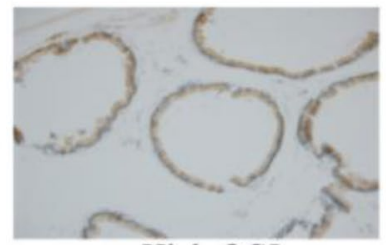

High-QCJ

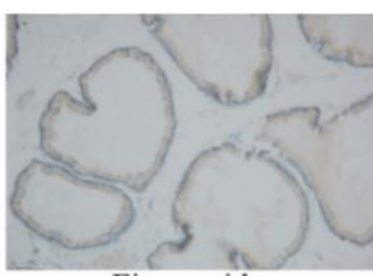

Finasteride

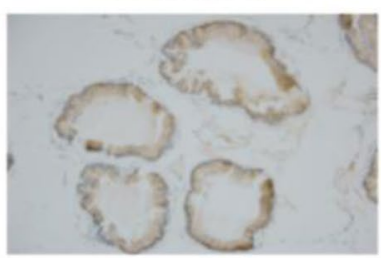

Low-Fr. B

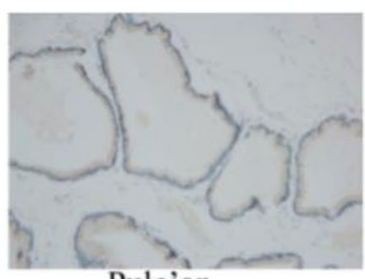

Pule'an

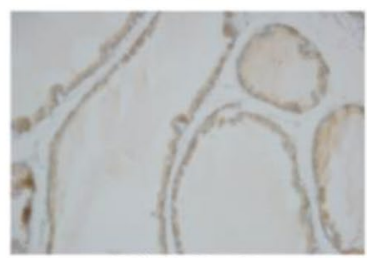

High-Fr. B

b

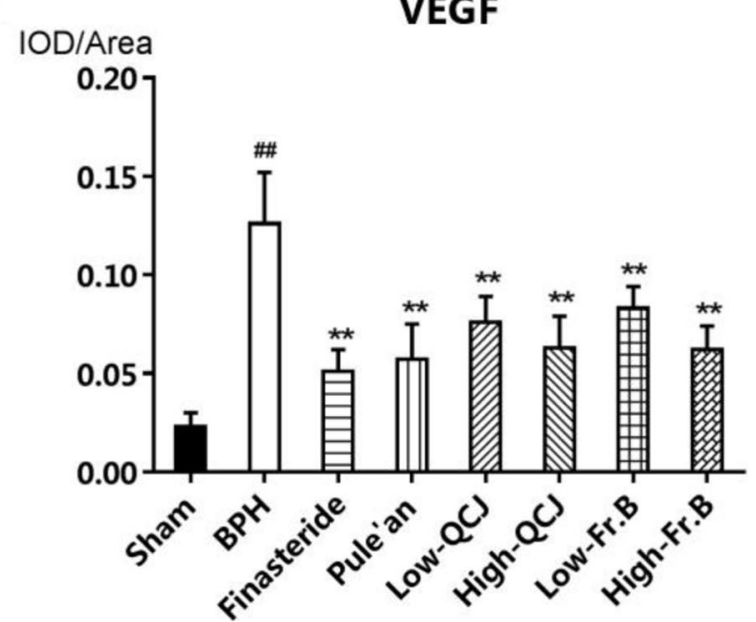

Fig. 2 Effects of QCJ and Fr. B onprostatic histopathology morphology (a) and the expression of VEGF (b) in BPH rats. \# $P<0.01$, versus Sham group; ${ }^{*} P<0.05,{ }^{* *} P<0.01$, versus $\mathrm{BPH}$ group

\section{Discussion}

Phytotherapy has been playing an important role in the treatment of $\mathrm{BPH}$ for over decades because of its mildness, effectiveness and low adverse effects. Lots of the researchers revealed that several kinds of constituents including the fatty acids, polyphenols, flavonoids, phytosterols, alkanoids may be responsible for $\mathrm{BPH}$ inhibitory activities of phytotherapy and the suggested mechanisms includes $5 \alpha$-reductase inhibitor, $\alpha 1$-adrenoceptor antagonist, aromatase inhibitor, anti-androgen, growth factor inhibitor, and so on [23-25]. The special chemical structure of flavonoids makes them have good anti-BPH properties [26]. Total flavanol glycosides from Abacopteris penangiana and its acid hydrolysate [27], total flavonoid extract of Pteris multifida [15] and dihydroquercetin [28], were reported to exert $\mathrm{BPH}$ protective effect through regulating inflammatory responses and reducing oxidative stress. In this study, we found that the active fraction Fr. B of $P$. utilis leaves riched in flavanoids, of which 10 identified flavonoid glycosides accounted for $54.96 \%$ of all Fr. B substances, which contributed to BPH reduction by mechanisms related with anti-oxidant, antiinflammatory effect, reduction of DHT/E2 ratio, and inhibition of growth factor. Among these 10 identified flavonoid glycosides, 4 compounds are kaempferol-O-glycosides (peak 2, 4, 6, 9), 3 compounds are quercetin-O-glycosides (peak $1,3,8$ ), and 3 compounds are isorhamnetin-O-glycosides (peak $5,7,10$ ). It was reported that kaempferol exhibited its androgeniclike activity and served as a selective androgen receptor modulator that contributed to androgen-related $\mathrm{BPH}$ development [29]. Kaempferol was revealed to be much better inhibitor of the type 2 than type 1 isozyme, quercetin was proved to be a potent inhibitor of the type $15 \alpha$-reductase [30]. Moreover, kaempferol 
a

mg/h

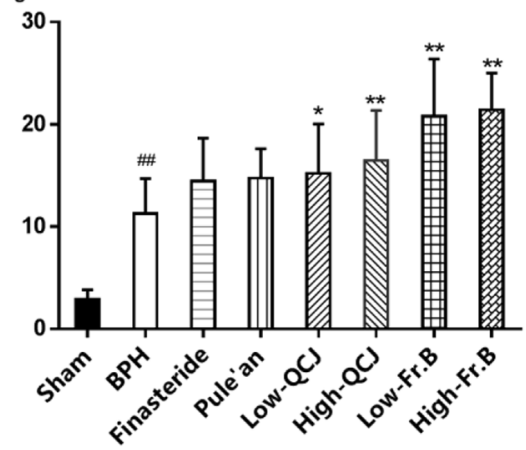

C

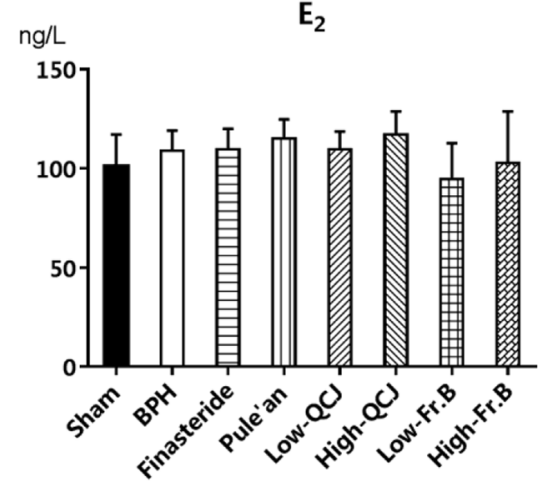

b

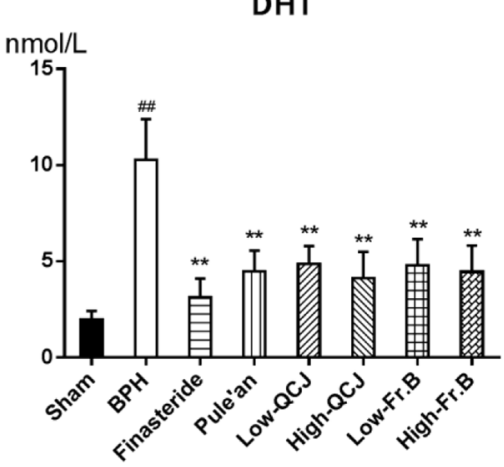

d

$\mathrm{mol} / \mathrm{mg} \quad \mathrm{DHT}_{2} \mathrm{E}_{2}$

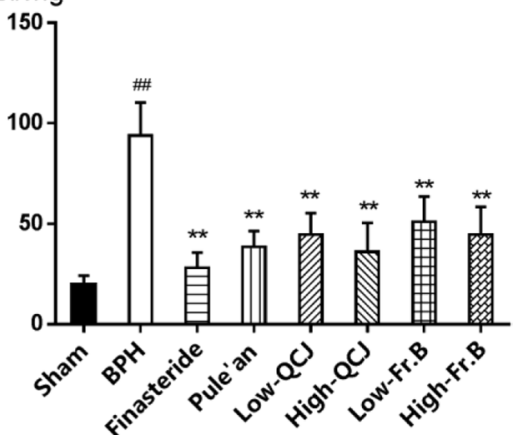

Fig. 3 Effects of QCJ and Fr. B on the levels of $\mathrm{DHT}(\mathbf{a}), T(\mathbf{b}), E_{2}(\mathbf{c})$ and $\mathrm{DHT} / \mathrm{E}_{2}(\mathbf{d})$ in serum of BPH rats. ${ }^{\# \#} P<0.01$, versus Sham group; ${ }^{*} P<0.05$, ${ }^{* *} P<0.01$, versus $B P H$ group

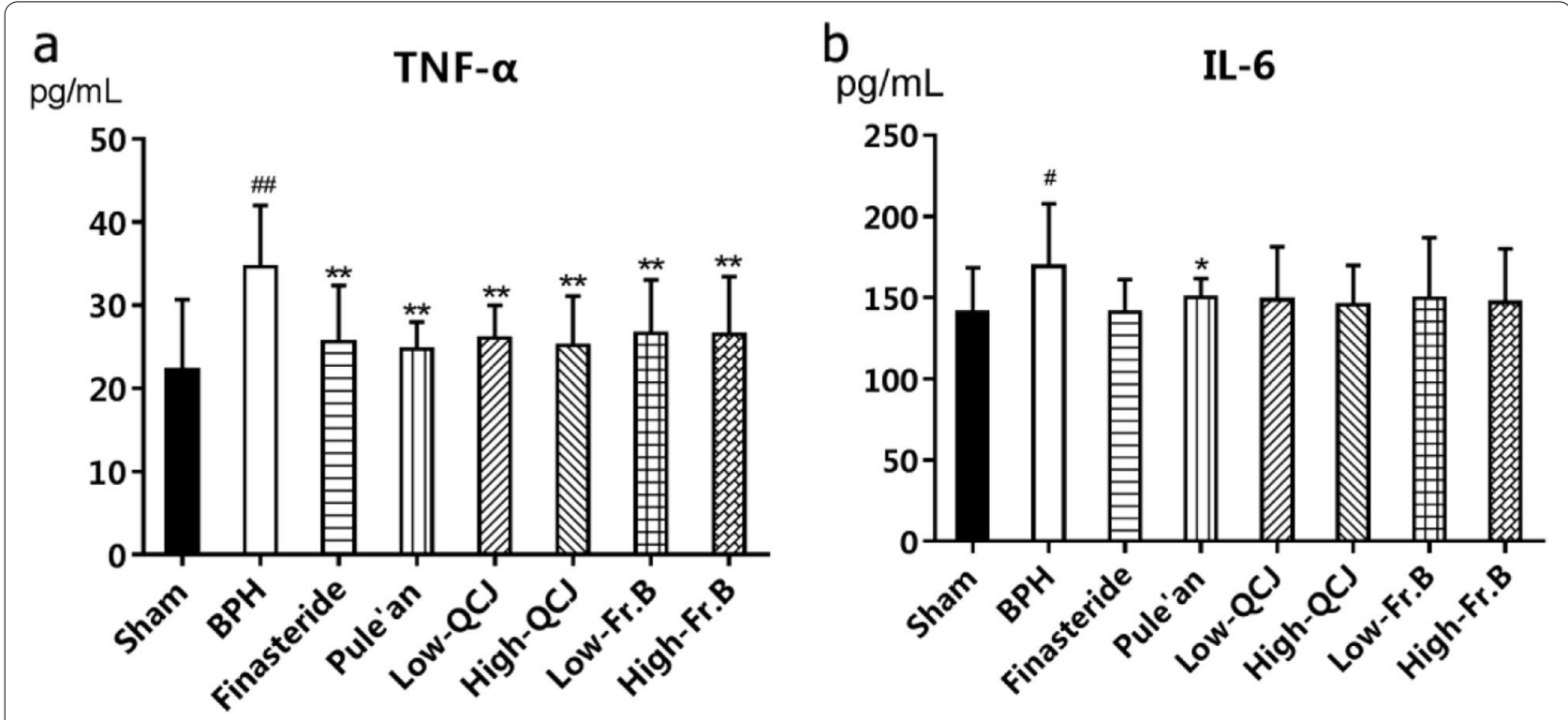

Fig. 4 Effects of QCJ and Fr. B on the levels of TNF-a (a) and IL-6 (b) in serum of BPH rats. ${ }^{\#} P<0.05,{ }^{\# \#} P<0.01$ versus Sham group; ${ }^{*} P<0.05$, ${ }^{* *} P<0.01$, versus $\mathrm{BPH}$ group 

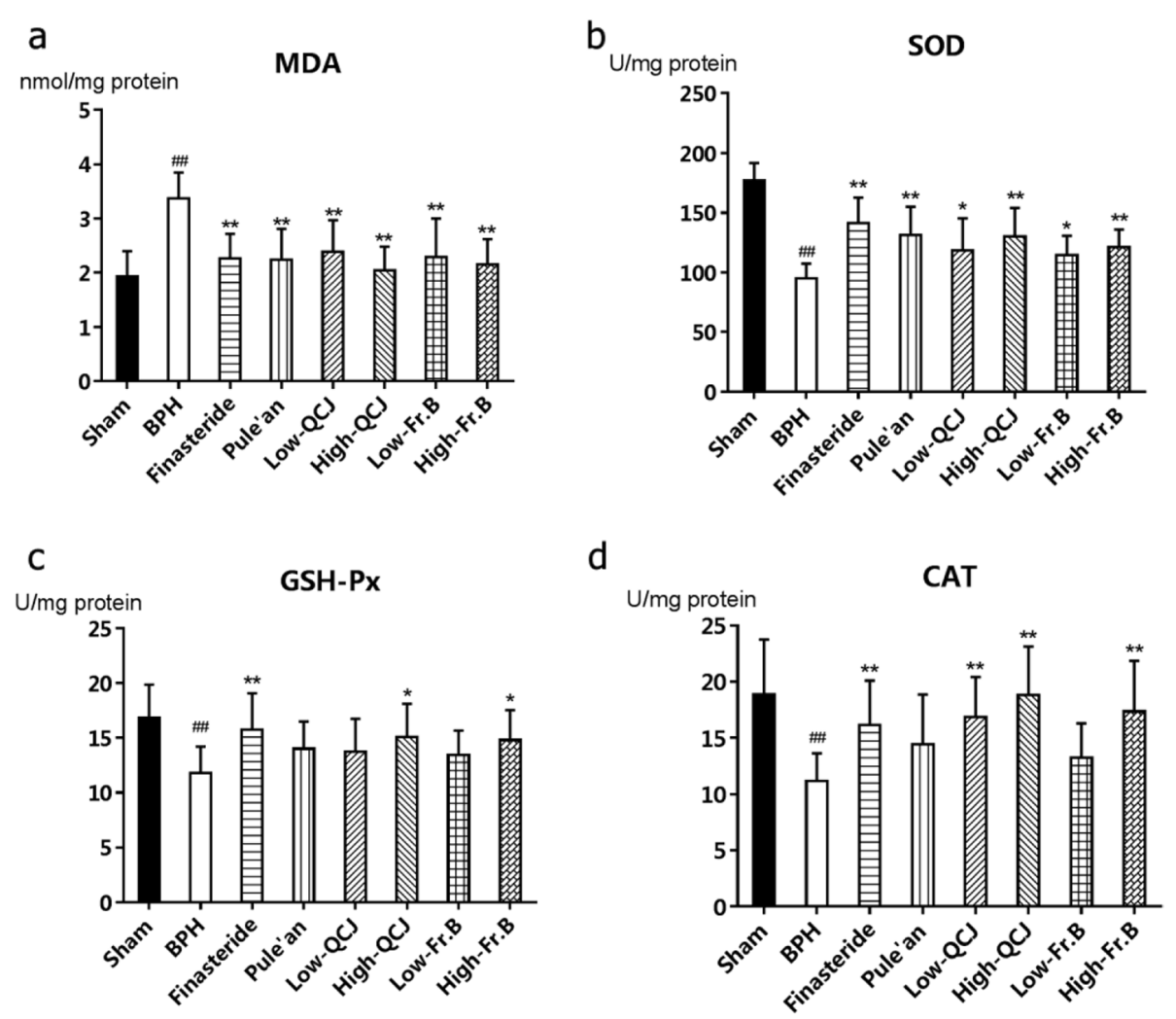

Fig. 5 Effects of QCJ and Fr. B on oxidative stress parameters in prostate tissue of rats. a MDA; b SOD; c GSH-Px; $\mathbf{d} C A T$; \#\# $P<0.01$, versus Sham group; ${ }^{*} P<0.05,{ }^{* *} P<0.01$, versus $B P H$ group

and its glycosides (kaempferol3-(3-E-p-coumaroyl$\alpha$-L-rhamnopyranoside), kaempferol 3-(2,3-di-E-pcoumaroyl- $\alpha$-L-rhamnopyranoside)) from the pollen of Brassica napus L. were found to exhibit down-regulation of prostate specific antigen in $\mathrm{LNCaP}$ cells [31]. Yin et al [32] once reported the kaempferol-3-O$\alpha$-L-rhamnopyranosyl- $(1 \rightarrow 6)-\beta$-D-glucopyranoside isolated from the Adina rubella leaves, the extract of which exhibited anti-oxidative and anti-inflammatory activities and $5 \alpha$-reductase inhibition associated with BPH. Similarly, Epilobium angustifolium exhibited the therapeutic potential against $\mathrm{BPH}$, and its active compounds included both kaempferol and quercetin as well as their glycosides [33]. The chemical investigation of the aerial parts of the fern Asplenium ceterach, one traditional medicine to treat $\mathrm{BPH}$, revealed the presence of kaempferol and quercetin glycosides [34]. In addition, two quercetin glycosides (quercetin5-O$\beta$-D-glucopyranoside, quercetin 3-O- $\beta$-L-rhamnopyranoside) are the main active components against anti-BPH of aqueous extracts from Saxifraga stolonifera [35]. So, the flavonoid glycosides identified from Fr. B should be potential anti-BPH ingredients of $P$. utilis, for further purification and pharmacological investigation.

In vitro and in vivo studies describe oxidative stress as a major pathway involved in the occurrence of $\mathrm{BPH}$ [36, 37]. High plasma peroxide levels were found in $\mathrm{BPH}$ patients compared with controls [38, 39]. Circulating MDA levels were found to be significantly higher in $\mathrm{BPH}$ patients than in healthy donors [38]. However, other works found circulating MDA levels in BPH patients similar to those in controls [36]. In our study, the level of MDA in prostate of BPH rats was significantly increased, indicating the prostate tissue was in a state of oxidative damage. Fr. B could significantly decrease the level of MDA in prostate of BPH rats. Normally, highly oxidative stresses are removed by natural protective mechanism, the superoxide dismutase enzyme system, such as SOD, GSH-Px and CAT [17, 40, 41]. Fr. B could significantly increase the content of antioxidant enzymes (SOD, GSHPx and CAT) and enhance the antioxidant capacity of rats. Prostate enlargement due to chronic inflammatory process may progressively conduce to $\mathrm{BPH}$ progression. Therefore, inflammation is a therapeutic target for $\mathrm{BPH}$ [42]. Although Fr. B had no significant decrease in serum 
IL-6 in BPH rats, it had a significant effect on TNF- $\alpha$, suggesting its potential to improve $\mathrm{BPH}$-related inflammation. These results suggested that Fr. B attenuate symptoms of $\mathrm{BPH}$, at least in part, by decreasing the proinflammatory cytokines secretion and oxidative stress.

In addition, androgens are essential for the development and differentiated function of the prostate, as well as for proliferation and survival of prostatic cells [43, 44]. It is clear that androgens, estrogens [45] and growth factors [46] contribute to the $\mathrm{BPH}$, but the exact etiology remains unknown. In this study, increased DHT levels and decreased T levels, as well as increased DHT/ $\mathrm{E}_{2}$ resulting from $\mathrm{BPH}$ induction, were significantly improved by Fr. B treatment. This reflected the androgens regulation potential mechanism of Fr. B on treating $\mathrm{BPH}$. Recently, increasing evidences suggested that prostate growth was under the indirect control of androgens through the mediation of different growth factors [47]. VEGF is a major inducer of angiogenesis as it influences endothelial cell growth. The immunohistochemical assay showed that the expression of VEGF in the prostatic tissue with BPH rats were significantly increased compared normal prostatic tissue [48]. We also found that Fr. B could significantly decrease the expression of VEGF in prostate tissue of BPH rats. Its specific mechanism and signal pathway need to be further discussed.

\section{Conclusion}

Collectively, the results of present study showed that Fr. B prepared from the water extract of $P$. utilis leaves attenuated symptoms of BPH through multiple mechanisms including reduction of DHT/E2 ratio, inhibition of growth factor, anti-inflammation and anti-oxidation. Ten flavonoids were assigned from Fr. B by UPLC-QTOFMS. These results support that Fr. B should be further explored as a prospective natural foods or supplements for $\mathrm{BPH}$ treatment.

\begin{abstract}
Abbreviations
P. utilis: Prinsepia utilis Royle; BPH: Benign prostatic hyperplasia; QCJ: Water extract from P. utilis leaves; Fr. B: Fraction separated from QCJ; UPLC-QTOF-MS: Ultra performance liquid chromatography-quadrupole-time of flight-mass spectrometry; HPLC: High-performance liquid chromatography; DAD: Photodiode-array-detector; ESI: Electrospray ionization; MSE: Mass spectrometry elevated energy; VEGF: Vascular endothelial growth factor; DHT: Dihydrotestosterone; T: Testosterone; E2: Estradiol; TNF-a: Tumor necrosis factor-a; IL-6: Interleukin-6; MDA: Malondialdehyde; SOD: Superoxide dismutase; GSH-PX: Glutathione peroxidase; CAT: Catalase.
\end{abstract}

\section{Acknowledgements}

Not applicable.

\section{Authors' contributions}

Xiaobo Li designed the study and interpreted the results. Ying Peng and

Chongsheng Peng collected test data and drafted the manuscript. Yang Wu and Chongzhi Sun did the experiments. The author(s) read and approved the final manuscript.

Funding

Not applicable.

Availability of data and materials

All data analysed during this study are included in this published article. The datasets generated during this study are not publicly available but are available from the corresponding author on reasonable request.

\section{Declarations}

\section{Ethics approval and consent to participate}

Ethical approval for this study was obtained from the Laboratory Animal Welfare and Ethics Committee of Shanghai Jiao Tong University, China. The animal care and experimental procedures were carried out in accordance with the Guidelines of the Animal Care and Use Committee of Shanghai Jiao Tong University, China.

\section{Consent for publication}

Not applicable.

\section{Competing interests}

The authors declared no conflict of interest.

Received: 29 June 2021 Accepted: 12 October 2021

Published online: 29 October 2021

\section{References}

1. Lan M. Materia medicalo of Yunnan. Kunming: People's Publishing House of Yunnan; 1975.

2. Gupta R, Goyal R, Bhattacharya S, Dhar KL. Antioxidative in vitro and antiosteoporotic activities of Prinsepia utilis Royle in female rats. Eur J Integr Med. 2015;7(2):157-63. https://doi.org/10.1016/j.eujim.2014.10.002.

3. Yang Y, Liu G, Zhang XY, Hu TT, Wang ZG, Li X, et al. Effect of Prinsepia utilis tea on blood lipids in hyperlipidemic mice. Sci Tech Food Industry. 2015;36(13):361-3.

4. Bin G. Studies on the chemical constituents of Prinsepia utilis Royle and anti-tumor activity. Shanghai: Shanghai Jiao Tong University; 2013.

5. Wang YJ, Zhang Y, Du J, Yang LJ, Zhang Q, Sun QQ, et al. Study on the anti-inflammatory active constituents of Prinsepia utilis. West China J Pharm Sci. 2006;21(2):152-4.

6. $P u Z H$, Yin $Z Q$, Jia $R Y$, Song $X, X u J$, Wang $X Q$, et al. Preliminary isolation and antibacterial activity of the ethyl acetate extract of Prinsepia utilis Royle in vitro. Agric Sci. 2014;5(6):540-5. https://doi.org/10.4236/as.2014. 56056.

7. Paterniti I, Campolo M, Cordaro M, Siracusa R, Filippone A, Esposito E, et al. Effects of different natural extracts in an experimental model of benign prostatic hyperplasia (BPH). Inflamm Res. 2018;67(7):617-26. https://doi.org/10.1007/s00011-018-1152-9.

8. Keehn A, Taylor J, Lowe FC. Phytotherapy for benign prostatic hyperplasia. Curr Urol Rep. 2016;17(7):53. https://doi.org/10.1007/s11934-016-0609-z.

9. Minciullo PL, Inferrera A, Navarra M, Calapai G, Magno C, Gangemi S. Oxidative stress in benign prostatic hyperplasia: a systematic review. Urol Int. 2015;94(3):249-54. https://doi.org/10.1159/000366210.

10. Wu Y, Peng Y, Peng CS, Guan H, Sun CZ, Li XB. Screening active components from Prinsepia utilis Royle leaves for combating benign prostatic hyperplasia in rats. Modern Food Sci Tech. 2019;35(3):46-51.

11. Guan H. Effects of Prinsepia utilis Royle leaves on benign prostatic hyperplasia. Shanghai: Shanghai Jiaotong University; 2017.

12. Zhan SQ, Yuan DS, Li XT, Li JL, Yin ZQ. Identification and determination of Total flavonoids from Prinsepia utilis Royle. Med Plant. 2010;1(10):12-5.

13. Zuo AH, Wei $\mathrm{QH}$, Zeng YE, Jiang B, Yang J. Determination of the total flavones content in Prinsepia utilis Royle with ultraviolet spectrophotometry. Yunnan J Trad Chinese Med Mater Med. 2008:29(6):43-4.

14. Zhang X, Jia Y, Ma Y, Cheng G, Cai S. Phenolic composition, antioxidant properties, and inhibition toward digestive enzymes with molecular 
docking analysis of different fractions from Prinsepia utilis Royle fruits. Molecules. 2018;23(12):3373. https://doi.org/10.3390/molecules231233 73.

15. Dai GC, Hu B, Zhang WF, Peng F, Wang R, Liu Z, et al. Chemical characterization, anti-benign prostatic hyperplasia effect and subchronic toxicity study of total flavonoid extract of Pteris multifida. Food Chem Toxicol. 2017;108(Pt B):524-31. https://doi.org/10.1016/j.fct.2016.11.010.

16. Wei $H$, Wu G, Shi D, Song S, Zhang X, Lei Y, et al. Total flavan glycoside from Abacopteris penangiana rhizomes and its acid hydrolysate: characterisation and anti-benign prostatic hyperplasia potential. Food Chem. 2012;134(4):1959-66. https://doi.org/10.1016/j.foodchem.2012.03.128.

17. Ammar AE, Esmat A, Hassona MD, Tadros MG, Abdel-Naim AB, Guns EST. The effect of pomegranate fruit extract on testosterone-induced $\mathrm{BPH}$ in rats. Prostate. 2015;75(7):679-92. https://doi.org/10.1002/pros.22951.

18. Bian Q, Wang W, Wang N, Peng Y, Ma W, Dai R. Arachidonic acid metabolomic study of BPH in rats and the interventional effects of Zishen pill, a traditional Chinese medicine. J Pharm Biomed Anal. 2016;128:149-57. https://doi.org/10.1016/j.jpba.2016.05.027.

19. Lyu Q, Kuo TH, Sun C, Chen K, Hsu CC, Li X. Comprehensive structural characterization of phenolics in litchi pulp using tandem mass spectral molecular networking. Food Chem. 2019;282:9-17. https://doi.org/10. 1016/j.foodchem.2019.01.001

20. Ji S, He DD, Wang TY, Han J, Li Z, Du Y, et al. Separation and characterization of chemical constituents in Ginkgo biloba extract by off-line hydrophilic interaction $\times$ reversed-phase two-dimensional liquid chromatography coupled with quadrupole-time of flight mass spectrometry. J Pharm Biomed Anal. 2017;146:68-78. https://doi.org/10.1016/j.jpba.2017.07.057.

21. Carson C 3rd, Rittmaster R. The role of dihydrotestosterone in benign prostatic hyperplasia. Urology. 2003;61(4Suppl1):2-7. https://doi.org/10. 1016/s0090-4295(03)00045-1.

22. Sun H, LiTJ, Sun LN, Qiu Y, Huang BB, Yi B, et al. Inhibitory effect of traditional Chinese medicine Zi-Shen pill on benign prostatic hyperplasia in rats. J Ethnopharmacol. 2008;15(2):203-8. https://doi.org/10.1016/j.jep. 2007.09.026.

23. Zhang $H$, Jing $Y, W u G$. Inhibitory effects of crude polysaccharides from semen vaccariae on benign prostatic hyperplasia in mice. J Ethnopharmacol. 2013;145(2):667-9. https://doi.org/10.1016/j.jep.2012.11.027.

24. Pagano E, Laudato M, Griffo M, Capasso R. Phytotherapy of benign prostatic hyperplasia. A minireview. Phytother Res. 2014;28(7):949-55. https:// doi.org/10.1002/ptr.5084.

25. Ullah R, Wazir J, Hossain MA, Diallo MT, Khan FU, Ihsan AU, et al. A glimpse into the efficacy of alternative therapies in the management of benign prostatic hyperplasia. Wien Klin Wochenschr. 2021;133(3-4):153-62. https://doi.org/10.1007/s00508-020-01692-z

26. Brown DM, Kelly GE, Husband AJ. Flavonoid compounds in maintenance of prostate health and prevention and treatment of cancer. Mol Biotechnol. 2005;30(3):253-70. https://doi.org/10.1385/MB:30:3:253.

27. Yang $X$, Yuan L, Xiong C, Yin C, Ruan J. Abacopteris penangiana exerts testosterone-induced benign prostatic hyperplasia protective effect through regulating inflammatory responses, reducing oxidative stress and anti-proliferative. J Ethnopharmacol. 2014;157:105-13. https://doi. org/10.1016/j.jep.2014.09.025.

28. Borovskaya TG, Krivova NA, Zaeva OB, Fomina TI, Kamalova SI, Poluektova ME, et al. Dihydroquercetin effects on the morphology and antioxidant/Prooxidant balance of the prostate in rats with Sulpirideinduced benign hyperplasia. BullExp Biol Med. 2015;158(4):513-6. https://doi.org/10.1007/s10517-015-2797-9.

29. Wang X, Zhu J, Yan H, Shi M, Zheng Q, Wang Y, et al. Kaempferol inhibits benign prostatic hyperplasia by resisting the action of androgen. Eur J Pharmacol. 2021;907:174251. https://doi.org/10.1016/j.ejphar. 2021.174251

30. Hiipakka RA, Zhang HZ, Wei D, Dai Q, Liao S. Structure-activity relationships for inhibition of human 5 alpha-reductases by polyphenols. Biochem Pharmacol. 2002;63(6):1165-76. https://doi.org/10.1016/ S0006-2952(02)00848-1.

31. Han HY, Shan S, Zhang X, Wang NL, Lu XP, Yao XS. Down-regulation of prostate specific antigen in LNCaP cells by flavonoids from the pollen of Brassica napus L. Phytomedicine. 2007;14(5):338-43. https://doi.org/ 10.1016/j.phymed.2006.09.005.
32. Yin J, Heo JH, Hwang YJ, Le TT, Lee MW. Inhibitory activities of phenolic compounds isolated from Adina rubella leaves against 5 a-Reductase associated with benign prostatic hypertrophy. Molecules. 2016;21(7):887. https://doi.org/10.3390/molecules21070887.

33. Deng L, Zong W, Tao X, Liu S, Feng Z, Lin Y, et al. Evaluation of the therapeutic effect against benign prostatic hyperplasia and the active constituents from Epilobium angustifolium L. J Ethnopharmacol. 2019;232:1-10. https://doi.org/10.1016/j.jep.2018.11.045.

34. Tomou EM, Skaltsa H. Phytochemical investigation of the Fern Asplenium ceterach (Aspleniaceae). Nat Prod Commun. 2018;13(7):849-50. https://doi.org/10.1177/1934578X1801300715.

35. Wu XD, Chen HG, Zhou X, Huang Y, Hu EM, Jiang ZM, et al. Studies on chromatographic fingerprint and fingerprinting profile-efficacy relationship of Saxifraga stolonifera Meerb. Molecules. 2015;20(12):2278198. https://doi.org/10.3390/molecules201219882.

36. Minciullo PL, Inferrera A, Navarra M, Calapai G, Magno C, Gangemi S. Oxidative stress in benign prostatic hyperplasia: a systematic review. Urol Int. 2015;94(3):249-54. https://doi.org/10.1159/000366210.

37. Roumeguère T, Sfeir J, El Rassy E, Albisinni S, Van Antwerpen P, Boudjeltia KZ, et al. Oxidative stress and prostatic diseases. Mol Clin Oncol. 2017;7(5):723-8. https://doi.org/10.3892/mco.2017.1413.

38. Kaya E, Ozgok Y, Zor M, Eken A, Bedir S, Erdem O, et al. Oxidative stress parameters in patients with prostate cancer, benign prostatic hyperplasia and asymptomatic inflammatory prostatitis: a prospective controlled study. Adv Clin Exp Med. 2017;26(7):1095-9. https://doi.org/ $10.17219 /$ acem/66837.

39. Pace G, Di Massimo C, De Amicis D, Corbacelli C, Di Renzo L, Vicentini C, et al. Oxidative stress in benign prostatic hyperplasia and prostate cancer. Urol Int. 2010;85(3):328-33. https://doi.org/10.1159/000315064.

40. Ahmad M, Suhail N, Mansoor T, Banu N, Ahmad S. Evaluation of oxidative stress and DNA damage in benign prostatic hyperplasia patients and comparison with controls. Indian J Clin Biochem. 2012;27(4):385-8. https://doi.org/10.1007/s12291-012-0229-4.

41. Aydin A, Arsova-Sarafinovska Z, Sayal A, Eken A, Erdem O, Erten K, et al. Oxidative stress and antioxidant status in non-metastatic prostate cancer and benign prostatic hyperplasia. Clin Biochem. 2006;39(2):176-9. https://doi.org/10.1016/j.clinbiochem.2005.11.018.

42. Robert G, Descazeaud A, Nicolaïew N, Terry S, Sirab N, Vacherot F, et al. Inflammation in benign prostatic hyperplasia: a 282 patients' immunohistochemical analysis. Prostate. 2010;69(16):1774-80. https://doi.org/ 10.1002/pros.21027.

43. Banerjee PP, Banerjee S, Brown TR, Zirkin BR. Androgen action in prostate function and disease. Am J Clin Exp Utol. 2018;6(2):62-77.

44. Miao M, Wang T, Liu J, Li Y, Fu Z, Tian S. The effect of Leonuri Herba alkaloids on senile BPH (male and female hormone induced) model rats. Saudi J Biol Sci. 2017;24(3):630-3. https://doi.org/10.1016/j.sjbs.2017. 01.035 .

45. Ho CK, Habib FK. Estrogen and androgen signaling in the pathogenesis of BPH. Nat Rev Urol. 2011;8(1):29-41. https://doi.org/10.1038/nrurol. 2010.207.

46. Al-Trad B, Al-Zoubi M, Qar J, Al-Batayneh K, Hussien E, Muhaidat R, et al. Inhibitory effect of Thymoquinone on testosterone-induced benign prostatic hyperplasia in Wistar rats. Phytother Res. 2017;31(12):1910-5. https:// doi.org/10.1002/ptr.5936.

47. Soulitzis N, Karyotis I, Delakas D, Spandidos DA. Expression analysis of peptide growth factors VEGF, FGF2, TGFB1, EGF and IGF1 in prostate cancer and benign prostatic hyperplasia. Int J Oncol. 2006;29(2):305-14.

48. Wu X, Gu Y, Li L. The anti-hyperplasia, anti-oxidative and anti-inflammatory properties of Qing ye Dan and swertiamarin in testosterone-induced benign prostatic hyperplasia in rats. Toxicol Lett. 2017;265:9-16. https:// doi.org/10.1016/j.toxlet.2016.11.011.

\section{Publisher's Note}

Springer Nature remains neutral with regard to jurisdictional claims in published maps and institutional affiliations. 